\title{
Seen but not heard - ethnic minorities' views of primary health care interpreting provision: a focus group study
}

\author{
Duncan S. Barron ${ }^{1}$, Caroline Holterman ${ }^{2}$, Pieter Shipster ${ }^{3}$, Sherma Batson ${ }^{4}$ and Mohammed Alam ${ }^{5}$ \\ ${ }^{1}$ NIHR Research Design Service for the East Midlands, Northampton, UK \\ ${ }^{2}$ North East Lincolnshire Care Trust Plus, Grimsby, UK \\ ${ }^{3}$ East and North Hertfordshire Primary Care Trust, Letchworth Garden City, UK \\ ${ }^{4}$ Stevenage World Forum, Stevenage, UK \\ ${ }^{5}$ North Herts Minority Ethnic Forum, Hitchin, UK
}

\begin{abstract}
Aim: The aim of this study was to explore the awareness and views of members of the ethnic minority community towards primary health care interpreting provision in two localities in Hertfordshire. Background: Ethnic minority groups often have to undertake many aspects of their day-to-day lives with limited English. The provision of high quality language interpretation services is vital for enabling access to public services, including healthcare. The use of accredited or professional interpreters has been minimal within primary care and undermines the principle of equity in the National Health Service. The local Primary Care Trust and ethnic minority forums initiated this study. Methods: The overall research design was qualitative and data collection was undertaken using focus groups. Twenty-four participants from the Pakistani (Punjabi and Urdu speakers), Bangladeshi (Bengali speakers) and Chinese (Cantonese and Mandarin speakers) communities took part in one of five focus groups. Ethnic minority members recruited participants, conducted the focus groups and translated the interviews after receiving in-depth training. Findings: Participants were unaware that healthcare professionals could access interpreting provision for their primary health care consultations, which were usually managed with the assistance of family members (including children) and friends. Both the appropriateness of using children and the potential compromising of confidentiality and privacy when using friends to interpret were concerns. Women discussed inventing illnesses rather than talking openly about embarrassing health issues in front of their children or husbands, which they suggested, may lead to depression or other mental health problems. Trust, accuracy, independence and confidentiality were important attributes participants expected in a professional interpreter whom they would prefer was from their own gender and culture.
\end{abstract}

Key words: ethnic minorities; focus groups; interpreting provision; primary health care

Received 19 August 2008; accepted 17 May 2009; first published online

28 January 2010

Correspondence to: Duncan S. Barron, R\&D Advisor, RDSEM, Centre for Health and Wellbeing Research, Park Campus, Boughton Green Road, Northampton NN2 7AL, UK. Email: Duncan.barron@northampton.ac.uk

(C) Cambridge University Press 2010

\section{Introduction}

The United Kingdom (UK) is a multi-ethnic, multi-lingual society (Baker and Eversley, 2000; Sanders, 2000) resulting from increased migration 
(Wallin and Ahlström, 2006). Ethnic minority groups often have to undertake many aspects of their day-to-day lives with limited English or a mix of English with their first language (Roberts et al., 2005). The provision of high quality language interpretation services is therefore vital for fostering social inclusion and enabling access to public services, including healthcare.

In primary care, the use of accredited or professional interpreters has been minimal (Lam and Green, 1994; Gerrish, 2001; Gerrish et al., 2004) undermining the principle of equity in the National Health Service (NHS) (Aspinall, 2007). Family members, including bilingual children, are often called upon to provide an informal interpreting service within primary care (Free et al., 1999; Free et al., 2003; Rhodes and Nocon, 2003). Children, however, may have insufficient competence in either language to interpret accurately (Free et al., 1999) or the emotional maturity to deal with the burden of sensitive health issues (Gerrish et al., 1996; Green et al., 2005).

The interpreting need is also met by many overseas trained, bilingual general practitioners (GPs) (Gill and Quirke, 2007) and nurses (ElderkinThompson et al., 2001) who play an important role in providing healthcare to many patients whose first language is not English (Knox and Britt, 2002). However, many overseas trained GPs are due to retire imminently (Gill and Quirke, 2007).

A lack of trust has emerged as the main barrier to communication in qualitative studies of interpreted consultations in primary care in the UK (Gerrish, 2001; Alexander et al., 2004; Robb and Greenhalgh, 2006). Other perceived personal qualities of the interpreter (such as being gentle, caring, empathetic, respectful and non-judgemental) are closely associated with the establishment of trust between the patient and the interpreter (Gerrish, 2001).

\section{Rationale for the present research}

This study focuses on two localities within Hertfordshire, an area of the South East, north of London where approximately $6.6 \%$ of the population are from a non-White ethnic minority background (ONS, 2001). Previous research has tended to concentrate on areas with large Black and Minority Ethnic (BME) populations such as
London (eg, Free et al., 2003; Alexander et al., 2004; Robb and Greenhalgh, 2006), Bradford (eg, Rhodes and Nocon, 2003) and the West Midlands (eg, Johnson et al., 1983; Brooks et al., 2000; Kai et al., 2007). This research is an important contribution to BME interpreting needs with regards to primary health care provision particularly among smaller populations of under-researched local ethic minority groups. Such groups are likely to face different but equally challenging issues when accessing primary health care than larger BME communities in other areas of the UK.

Professional primary health care interpreting services were available in the localities and provided by the commercial and voluntary sectors and consisted of a mix of telephone based or prior arranged person-to-person sessions that were accessed by the health care professional and paid for by the public services. The local Primary Care Trust (PCT) and ethnic minority forums identified the need for research in to the needs of local ethnic minority group members and approached the Hertfordshire Primary Care Network Consortium (HertNet) for research assistance and support.

The aim of this study was to explore the awareness and experiences of interpreting provision services for people whose first language is not English in relation to accessing primary health care in the two localities. To our knowledge this is the most comprehensive research to be undertaken, not just in the two localities, but also across the county.

\section{Design and method}

The overall research design was qualitative and data collection was undertaken using focus groups. Focus groups rely on the dynamic of group interactions to stimulate the thinking and the verbal contributions of participants who serve as expert informants and are used to seek opinions, values and beliefs in a collective and mutually supportive environment (Krueger, 1994; Morgan, 1997; Krueger and Casey, 2000).

Focus groups are increasingly used to access marginalized groups who may have inadequate literacy and/or language skills that may exclude them from participating in research utilizing validated instruments (Free et al., 1999; Clark et al., 2003; Halcomb et al., 2007). Altogether five focus 
groups comprising between two and seven participants were conducted. Groups were run in comfortable, warm venues known to the participants. The local Hertfordshire NHS research ethics committee and PCT research management and governance approvals were obtained.

\section{Participants}

Participants were recruited from a wide section of the local ethnic minority community via word of mouth and appeals to local ethnic minority group leaders and groups. A total of 24 participants agreed to take part in one of five focus groups. The majority were female $(n=23)$ and approximate ages ranged from 28 to 72 years. The groups included: three Pakistani groups $(n=11)$ including two Punjabi speaking groups and one Urdu speaking group, one Bangladeshi (Bengali speaking) group $(n=6)$ and one Chinese (Cantonese and Mandarin speaking) group $(n=7)$. Participants were offered shopping vouchers for taking part in the study. The demographic details of the sample are shown below in Table 1.

\section{Materials}

An interview guide was designed to elicit information around interpreting use within primary health care among ethnic minority groups. The guide was designed with the assistance of University and ethnic minority forum colleagues and health care professionals and was piloted extensively on members from the target ethnic minority groups. The interview schedule was translated by each focus group facilitator into the target language. The schedule covered the use of different types of interpreters in health care, attributes of a good interpreter and participants' experiences of accessing primary health care in the area.

\section{Focus group facilitators}

Members of the target ethnic minority communities were recruited as part of the research team. Facilitators were chosen who had some previous interviewing experience either in a research or professional capacity (eg, nursing and social
Table 1 Characteristics of focus group participants

\begin{tabular}{|c|c|}
\hline Focus group & Participants \\
\hline Pakistani Urdu & $\begin{array}{l}n=4 \text { (female) } \\
\text { Age range: } 40-62\end{array}$ \\
\hline Pakistani Punjabi 1 & $\begin{array}{l}n=5 \text { (female) } \\
\text { Age range: } 36-70\end{array}$ \\
\hline Pakistani Punjabi 2 & $\begin{array}{l}n=2 \text { (female) } \\
\text { Ages: } 45 \text { and } 65\end{array}$ \\
\hline $\begin{array}{l}\text { Chinese (Cantonese } \\
\text { and Mandarin) }\end{array}$ & $\begin{array}{l}n=7 \text { (male }=1 \text { aged } 72 \text { years) } \\
\text { Ages: } 35,44,65,66,67,67 \text { and } 72\end{array}$ \\
\hline Bangladeshi (Bengali) & $\begin{array}{l}n=6 \text { (Female) } \\
\text { Ages: } 28,40,45,50,60 \text { and } 62\end{array}$ \\
\hline $\begin{array}{l}\text { Total Focus } \\
\text { groups }=5\end{array}$ & Total $n=24$ \\
\hline
\end{tabular}

work) and who agreed to attend focus group facilitator training. Facilitators were responsible for recruiting participants (usually from preexisting groups already meeting in the community), facilitating the focus groups and providing an English translation of the focus group transcript. The facilitators were members of the same ethnic background and in some cases the same ethnic minority community groups as participants. Facilitators were instructed to attempt recruit participants that they did not already know, but in some cases this proved unrealistic. The facilitators were also instructed to target recruitment of members of their own gender to groups they ran. The aim was to conduct single sex focus groups facilitated by a member of the same gender. Facilitators were reimbursed for attending focus group training, running the focus groups and translating and transcribing the interviews. The background characteristics of the focus group facilitators are shown below in Table 2, and included one male and two females.

\section{Procedure}

Apart from the Chinese group, two facilitators conducted each group discussion. Group confidentiality was stressed to all participants. Signed informed consent was obtained from each participant prior to the commencement of each group. Participants were asked to introduce themselves to the group followed by a general question about, which health services, participants use and 
Table 2 Characteristics of the focus group moderators

\begin{tabular}{lcllll}
\hline $\begin{array}{l}\text { Focus group } \\
\text { facilitator }\end{array}$ & Age & Gender & $\begin{array}{l}\text { Cultural } \\
\text { background }\end{array}$ & $\begin{array}{l}\text { Languages } \\
\text { spoken }\end{array}$ & $\begin{array}{l}\text { Focus groups } \\
\text { facilitated }\end{array}$ \\
\hline $\begin{array}{l}\text { Kinsuk Roy } \\
\text { Charanjit Kang }\end{array}$ & 33 & $\begin{array}{l}\text { Male } \\
\text { Li Jun }\end{array}$ & $\begin{array}{l}\text { Bemale } \\
\text { Bndian (Sikh) }\end{array}$ & $\begin{array}{l}\text { Bengali, Punjabi, Urdu, English } \\
\text { Punjabi, Hindi, Urdu, English } \\
\text { Mandarin, English }\end{array}$ & $\begin{array}{l}\text { Urdu, Punjabi 1 and 2, Bengali } \\
\text { Chinesunjabi 1 and 2, Bengali }\end{array}$ \\
\hline
\end{tabular}

then moved to asking more specifically about use of and need for interpreters during their own health consultations with their doctor. The emphasis placed in each focus group was on participants' experiences within primary care (ie, with their GP). Sessions lasted approximately $30-60 \mathrm{~min}$. The interviews were recorded and later transcribed into English, each pair of facilitators cross-checking with each other for accuracy in the transcription. A subsample of participants was approached to comment on the accuracy of the transcripts.

\section{Method of analysis}

'Framework Analysis' (Ritchie and Spencer, 1994), which is a matrix-based method for ordering and summarizing data (Ritchie et al., 2003), was employed to analyse the focus group data. All the interviews were read and re-read, during which key themes were identified, numbered and indexed, resulting in a thematic framework (or index). The index was applied to the transcripts and field notes. Several versions of the index were refined and modified in an iterative process as new themes emerged from coding subsequent focus group interviews. Charts were created with columns representing the thematic framework (which comprised themes and sub themes), and the rows representing participants' views, which were cross-referenced to the original transcripts. The end result was a set of data structured within an analytical framework that was grounded in participants' own words enabling rapid review of the full pattern of responses across and within all focus groups for each theme.

\section{Findings}

The qualitative data are presented below as quotes from the group discussions. Each hyphen at the start of a sentence represents an individual speaking. A quote highlighting several hyphens at the start of each sentence indicates individual contributions to a group exchange.

\section{Awareness of local professional interpreting provision}

There was some knowledge among participants that interpreting provision was available for ethnic minorities when accessing local council services.

Maybe in other towns they have the facility but not here.

- ... I didn't know that it was available for medical service.

- I know about the general services. If we go to the council that is available as you can see the leaflets about it. But you can get the service in the GP's surgery? I didn't know that. I don't think anybody knows about it.

- ...No we never heard about it.

- I really do not know who they are.

(Bengali $F G$ )

Participants were completely unaware about the provision of local interpreting services, which could be accessed only by the healthcare professional, including telephone interpreting provision, for members of the ethnic community when accessing healthcare. Groups discussed wanting to know more about the local primary health care interpreting services on offer.

We do not know anything about [local interpreting services].

...Maybe there is somebody needed to teach us.

Nobody tell us about them. 
I do not know how to find these interpreting services indeed...

We need more information about the interpreters.

...I wish that foreign people could be given interpreting information when they register with a GP the first time.

Yes, that would be much easier for them to find an interpreter when they need one.

...We need more information about the interpreters.

(Chinese FG)

Several groups also felt that in their communities, shame can be attributed to seeking help:

Some people do not tell anyone, as it would be shameful thing if other people found out in the community.

(Urdu FG)

I think our community thinks that when we access support we are being negative and that we should not let people know about our personal situations.

(Punjabi FG)

\section{The use of family and friends to interpret}

As a result of not utilizing professional interpreters, focus group participants discussed relying on family members and friends to interpret for them when making a GP appointment or during the consultation. Children in particular were relied upon to interpret by focus group participants when seeing their GP. However, most groups discussed the inappropriateness of relying on children in this way.

If you take such a young child he or she does not have that capability to take on a role like this and it is not fair to put the child through an ordeal like this. We were desperate as there was often no other option. What will they understand and what will they translate? It is not fair to put children in this situation.

(Urdu FG)

Despite this, study participants said they feel they have no other option but to use their children to interpret for them during a GP consultation.
Privacy was a concern when friends are used to interpret.

We sometimes take other people we know who can speak English but we have to be careful, as we don't want everyone to know our business and our ailments. Sometimes there are sensitive and confidential matters that we don't want anyone else to know about.

(Urdu FG)

Another thing is that we do not want to let other people know our private things.

Yes.

I do not want let other people know I am seeing the doctor.

This is privacy.

Especially for some special diseases.

If a friend knows, maybe he will pass to another then another, maybe 5 to 10 people will know, you know this is not what we want.

(Chinese FG)

\section{Misunderstandings and embarrassing ailments}

Participants were concerned that using young children who may not have the adequate language skills to interpret may lead to the wrong diagnoses being made and the prescribing of incorrect medicines.

Some people like doctors sometimes use big words that we can't understand and our children can't understand so this becomes difficult. Sometimes the children take a guess and this is not ideal as they can miss what we are trying to say... When we answer what the doctors ask us often we have to repeat and can see that he looks confused. It is worrying if he gets it wrong and gives the wrong medicine.

(Urdu FG)

We also worried about medicine the doctor gave us when they did not know exactly what our problem was.

(Chinese FG)

Women were also embarrassed to discuss their ailments in front of their husbands, and on occasion make up pseudo-illnesses with their GP in 
their husbands' presence and as a result get prescribed inappropriate medications.

If things get too difficult we would just come without the medicine or get medicine for something else because it was too embarrassing to talk about the matter with our husbands there.

(Urdu FG)

The repercussions of not being able to discuss health-related issues (whether in the presence of children or husbands or through a lack of having a professional interpreter) was highlighted as a major concern by women, many of whom appeared fully aware of the negative ramifications this could have on their health.

Sometimes we women cannot even tell our husbands because it would not be appropriate and it feels like there is no one we can turn to. Often this makes us feel low and we do not know where to turn.

(Urdu FG)

I think sometimes because our people do not talk openly about their problems they create further health issues like depressions and low self-esteem.

(Punjabi FG)

Participants discussed mechanisms for managing a consultation with a GP when they did not have anyone to interpret for them. The Chinese focus group felt the use of pictures during consultations would benefit them when there is not an interpreter:

I think that the health settings can make some cards with a picture of the body so that we can point out where our health problem is.

Good idea.

\section{(Chinese FG)}

\section{Important interpreter attributes}

Participants spoke about the ideal qualities they would appreciate in a professional interpreter if one was to be made available to them. They needed to be able trust an interpreter both in terms of accurately conveying information to the health professional and in terms of not disclosing confidential information.

It would be very important for us to feel that we could rely on such interpreters, as it would be dreadful if our expectations were not met. Also, it is important that the interpreters are people who can be trusted and who respect confidentiality.

(Punjabi FG2)

Participants felt that trust would be more readily secured if the interpreter was professionally trained, acted independently, was accurate and understood medical terminology. It was also felt that only interpreters originating from participants own communities would be aware of cultural issues that govern many interactions between individuals from ethnic minorities.

The professionals have to be aware of our cultural needs and how our family function. Yes it is important that all service provision takes into account the cultural knowledge and appropriateness....

(Punjabi FG2)

The predominately female participants felt that only female interpreters would be suitable to interpret for their health needs.

Women understand women better and this is very important during any information exchange.

(Urdu FG)

Advocacy was an issue raised by participants in a few focus groups:

Yes I do expect that not only they interpret for me but they will speak for me too. That is very important. That can be very good help.

(Bengali FG)

\section{Discussion}

\section{Awareness of local professional interpreting services}

Awareness and use of local healthcare professional accessed interpreting provision in primary health care among study participants was nonexistent. Groups wanted more information on these services and felt that they should be more accessible by members of their communities. Some participants had used local interpreting services in other settings (eg, accessing council services), but no participants were aware that such services accessed by the healthcare professional 
were available for primary health care. It is assumed that some practices may also not be aware of local interpreting provision, which further research could explore. Some participants highlighted the stigma associated with seeking support including the help of an interpreter. Some members of the ethnic minority community may require assistance from health professionals and leaders of their communities to overcome the stigma associated with seeking support.

\section{The use of family and friends to interpret}

Participants managed their GP consultations without the aid of a professional interpreter, frequently relying on family members and friends to interpret. This is a consistent theme found in the literature (Free et al., 1999; Free et al., 2003; Rhodes and Nocon, 2003). The predominately female study participants discussed the inappropriateness of using children to communicate with their GP, acknowledging the heavy burden this places on them (Haffner, 1992). Participants were aware that children do not always have the necessary language skills or the emotional maturity to deal with the sometimes sensitive health issues of their parents or grandparents (Gerrish et al., 1996; Green et al., 2005), and were worried that this could lead to the wrong diagnoses being made and the incorrect medicines being prescribed. Future research should attempt to explore primary health care professionals' views of the use of children to interpret during their parent's consultations. There was also the view that privacy and confidentiality could be undermined if friends were used as interpreters, since there was a fear that personal information would be divulged to the wider community.

\section{Misunderstandings and embarrassing ailments}

Most participants suggested that they feel embarrassed by discussing female personal health issues in front of their children and their husbands. This often prevents them talking openly about their health concerns (Gerrish, 2001). The fact that women do turn to male family members to interpret for them may indicate just how desperate they are at times to communicate with a GP.

Rather alarmingly participants spoke of inventing illnesses (cf. Haffner, 1992) and being prescribed medicines for a different ailment because it is too hard for them to discuss their true health issues in front of their husbands. Future research should explore this in more depth and include an evaluation of medicines user reviews led by community pharmacists (ideally who are members of the ethnic minority and who could speak the appropriate language).

Some participants discussed the implications of not being able to openly discuss their health needs with a GP, suggesting that this could lead to mental health problems such as depression and lack of self-esteem. This is an interesting finding when it is borne in mind that consultation rates for psychological disorders are low for most ethnic minorities particularly women (Balarajan et al., 1989). Psychological distress may be present in ethnic minorities but less easily detected by GPs (Knox and Britt, 2002: p. 101), something future research should explore. It may be that some ethnic minority groups' somatisize their psychological distress leading to higher consultations rates for other ailments.

\section{Important interpreter attributes}

Participants discussed attributes they felt are important in a professional interpreter. As in previous research, trust emerged as a central theme (cf. Robb and Greenhalgh, 2006). Participants wanted to be able to trust an interpreter to interpret accurately and they wanted to be confident that interpreters respected patient confidentiality. Other personal qualities participants wished to see in professional interpreters were that they were independent and aware of medical language. Focus group participants felt that an interpreter from their own cultural background was important. The predominately female participants discussed their preference for female interpreters from their own ethnic community who would be sympathetic to cultural and female issues.

\section{Strengths and limitations of the study}

A strength of this study was the involvement of members of the ethnic minority community to conduct the focus groups after receipt of training. However, it may be that the training input was underestimated. Some of the resulting focus group data was of limited quality because some facilitators did not gain a deeper understanding of the issues (cf. Clark et al., 2003). Facilitators were 
chosen who had some previous experiences of conducting professional or research interviews. More in-depth training would be advantageous in future research. The use of only one male focus group facilitator in a study that recruited predominately female participants may have impacted on the findings. Asian women may not have disclosed fully to a male facilitator.

Attempts to ensure the facilitators were not known by the focus group participants were not always successful, mainly because of the number of different groups to which some women belonged and because the facilitators came from the same local communities. The male facilitator experienced some suspicion among groups of men that he attempted to recruit and so he also attempted to recruit women where he was more successful. However, he was already known to many of the Urdu, Bengali and Punjabi speaking women he recruited via his long-established social work among these communities. The use of facilitators unknown to participants perhaps from outside of the research area would probably aid disclosure. The use of a male focus group facilitator with access and links to prominent male 'gate keepers' and elders or existing BME male groups would be advantageous in future research.

Focus groups seemed to work well with the current population. Focus groups have been recommended for use with marginalized groups or with those of limited literacy and/or language in the dominant culture (Halcomb et al., 2007). However, recruitment was problematic and took longer than anticipated. It has also been suggested that some cultural groups such as the Chinese might find discussing personal issues in a group at variance to cultural norms (Willgerodt, 2003). The Chinese focus group in this study produced the shortest interview. However, this could also be the result of the facilitator only speaking Mandarin and recruiting participants who spoke both Cantonese and Mandarin. The facilitator had to rely on an untrained group participant to interpret from Mandarin to Cantonese and vice versa. Future priority should be given to recruiting more Cantonese speakers and using a Cantonese speaking facilitator.

Confidentiality was an important issue for participants when discussing use of an interpreter and is likely to be an issue in the focus group setting where confidentiality is particularly difficult to enforce (Smith, 1995). However, confidentiality was stressed at the beginning of each focus group and was not raised as a concern by participants.

The voice of men from ethnic minority communities has to a large extent gone unheard in this study. This was in spite of attempts to recruit an equal balance of men and women via existing groups and community leaders. Further efforts should be concentrated on effective means of accessing and recruiting men from a range of ethnic minority communities with the involvement of religious leaders or other men's groups. For some populations such as Bangladeshi and Indian men the GP consultation rate is higher than the population as a whole (Gill et al., 2007) and therefore their views of accessing primary health care through the use of an interpreter are of interest.

Only one group each was run for both Chinese and Bangladeshi participants while three were run for Pakistani participants. No attempt is made to generalize from the findings of this small scale qualitative pilot study to the wider ethnic minority population of the areas under study, not least of all because of the over-representation of members of the female Pakistani community in this study. Future research should attempt to recruit a broader range of ethnic minorities including members of the Asian Indian, Black Caribbean and Black African communities. It is also worth considering the voice of other minorities who would benefit from interpreted GP consultations. For example the deaf community has often been overlooked (Stapleton, 2007) and interpreting need for health care among the 'other White' population is likely to have grown in view of increased immigration from Eastern European countries under the widening of the EU since 2004.

\section{Conclusion}

Despite being confined to a relatively small area in the south east of England, this research supports the findings of previous studies which report that interpreting services are inadequate in primary health care and a heavy and inappropriate reliance is placed on family members, especially children, to interpret (Gerrish et al., 1996; Gerrish, 2001). There is evidence to suggest that local providers need to publicize appropriately and 
more widely the interpreting services available for ethnic minorities for their primary health care needs both within primary care and among ethnic communities themselves, perhaps giving BME groups a say in how services are run. Ethnic minority patients with limited English require reassurance in the professional and personal attributes of primary health care interpreters. This may only be achieved when interpreters come from the same ethnic communities. Interpreting provision is a major barrier to accessing health services (including primary care) and effective communication between ethnic minorities and health professionals (Aspinall, 2007). Equity in access to primary health care will continue to be undermined by minimal availability and use of interpreting provision for ethnic minority groups.

\section{Acknowledgements}

The Hertfordshire Primary Care Research Network Consortium (HertNet) and the former North Hertfordshire and Stevenage PCT cofunded the study. The authors grateful to Li Jun, Charanjit Kang and Kinsuk Roy for their assistance with conducting the focus groups and to the participants who agreed to take part, and to the anonymous reviewers for their helpful comments on an earlier draft of this article.

\section{Conflict of interest}

Duncan Barron worked for HertNet, the Primary Care Research Network Consortium for Hertfordshire, which part-funded the study via its open funding competition that is subject to external peer review. DB provided methodological support and delivered the focus group training.

\section{References}

Alexander, C., Edwards, E. and Temple, B. 2004: Access to Services With Interpreters: Users' Views. London, UK: South Bank University.

Aspinall, P.J. 2007: Language ability: a neglected dimension in the profiling of populations and health service users. Health Education Journal 66, 90-106.

Baker, P. and Eversley, J. 2000: Multi-lingual Capital: the Languages of London's School Children and Their Relevance to Economic, Social and Educational Policies. London, UK: Battlebridge.

Primary Health Care Research \& Development 2010; 11: 132-141
Balarajan, R., Yuen, P. and Raleigh, V.S. 1989: Ethnic differences in general practitioner consultations. British Medical Journal 299, 958-60.

Brooks, N., Magee, P., Bhalti, G., Buckley, S., Guthrie, S., Moltesen, H., Moore, C. and Murray, S. 2000: Asian perspectives on the communication facilities provided in a large inner city hospital. Journal of Clinical Nursing 9, 706-12.

Clark, M.J., Cary, S., Diemart, G., Ceballos, R., Sifuentes, M., Atteberry, I., Vue, F. and Trieu, S. 2003: Involving communities in community assessment. Public Health Nursing 20, 456-63.

Elderkin-Thompson, V., Silver, R.C. and Waitzkin, H. 2001: When nurses double as interpreters in a US primary care setting. Social Science and Medicine 52, 1343-58.

Free, C., Green, J., Bhavnani, V. and Newman, A. 2003: Bilingual young people's experiences of interpreting in primary care: a qualitative study. British Journal of General Practice 53, 530-35.

Free, C., White, P., Shipman, C. and Dale, J. 1999: Access to and use of out-of-hours services by members of Vietnamese community groups in South London: a focus group study. Family Practice 16, 369-74.

Gerrish, K. 2001: The nature and effect of communication difficulties arising from interactions between district nurses and South Asian patients and their carers. Journal of Advanced Nursing 33, 566-74.

Gerrish, K., Chau, R., Sobowale, A. and Birks, E. 2004: Bridging the language barrier: the use of interpreters in primary care nursing. Health and Social Care in the Community 12, 407-13.

Gerrish, K., Husband, C. and Mackenzie, J. 1996: Nursing for a multi-ethnic society. Buckingham, UK: OU Press.

Gill, P.S., Kai, J., Bhopal, R.S. and Wild, S. 2007: Black and minority ethnic groups (3rd series). Health care needs assessment. The epidemiologically based needs assessment reviews. Retrieved 11 July 2008 from http://hcna.radcliffeoxford.com/bemgframe.htm

Gill, P.S. and Quirke, T. 2007: Urgent need for local data to meet the translation need. British Medical Journal, retrieved 11 July 2008 from: http:/www.bmj.com/cgi/ eletters/334/7590/398\#160766

Green, J., Free, C., Bhavnani, V. and Newman, T. 2005: Translators and mediators: bilingual young people's accounts of their interpreting work in health care. Social Science and Medicine 60, 2097-110.

Haffner, L. 1992: Translation is not enough - interpreting in a medical setting. In cross-cultural medicine - a decade later [special issue]. The Western Journal of Medicine 157, 255-59.

Halcomb, E.J., Gholizadeh, L., DiGiacomo, M., Phillips, J. and Davidson, P.M. 2007: Literature review: considerations in undertaking focus group research with culturally and linguistically diverse groups. Journal of Clinical Nursing 16, 1000-11. 
Johnson, M.R., Cross, M. and Cardew, S.A. 1983: Inner city residents, ethnic minorities and primary health care. Postgraduate Medical Journal 59, 664-67.

Kai, J., Beavan, J., Faull, C., Dodson, L., Gill, P. and Beighton, A. 2007: Professional uncertainty and disempowerment responding to ethnic diversity in health care: a qualitative study. Public Library of Science Medicine 4, e323, doi:10.1371/journal.med.0040323

Knox, S.A. and Britt, H. 2002: A comparison of general practice encounters with patients from English-speaking and non-English speaking backgrounds. Medical Journal of Australia 177, 98-101.

Krueger, R.A. 1994: Focus groups: a practical guide for applied research, second edition. London, UK: Sage.

Krueger, R.A. and Casey, M.A. 2000: Focus groups: a practical guide for applied research, third edition. London, UK: Sage.

Lam, T. and Green, J. 1994: Primary health care and the Vietnamese community: a survey in Greenwich. Health and Social Care 2, 293-99.

Morgan, D.L. 1997: Focus groups as qualitative research, second edition. London: Sage.

Office for National Statistics. 2001: 2001 Census: Key Statistics. Retrieved 11 July 2008 from http://www.neighbourhood. statistics.gov.uk/dissemination/

Rhodes, P. and Nocon, A. 2003: A problem of communication? Diabetes care among Bangladeshi people in Bradford. Health and Social Care in the Community 11, 45-54.
Ritchie, J. and Spencer, L. 1994: Qualitative data analysis for applied policy research. In Bryman, A. and Burgess, R.G., editors, Analyzing qualitative data, 173-94. London, UK: Routledge.

Ritchie, J., Spencer, L. and O'Connor, W. 2003: Carrying out qualitative analysis. In Ritchie, J. and Lewis, J., editors, Qualitative Research Practice, 219-62. London, UK: Sage.

Robb, N. and Greenhalgh, T. 2006: 'You have to cover up the words of the doctor'. The mediation of trust in interpreted consultations in primary care. Journal of Health Organization and Management 20, 434-55.

Roberts, C., Moss, B., Wass, V., Sarangi, S. and Jones, R. 2005 : Misunderstandings: a qualitative study of primary care consultations in multilingual settings, and educational implications. Medical Education 39, 465-75.

Sanders, M. 2000: As good as your word: a guide to community interpreting and translation in public services. London, UK: The Maternity Alliance.

Smith, M. 1995: Ethics in focus groups: a few concerns. Qualitative Health Research 5, 478-86.

Stapleton, E. 2007: What about the Deaf community? British Medical Journal. Retrieved 11 July 2008 from http:// www.bmj.com/cgi/eletters/334/7590/398\#160508

Wallin, A.-M. and Ahlström, G. 2006: Cross-cultural interview studies using interpreters: systematic literature review. Journal of Advanced Nursing 55, 723-35.

Willgerodt, M.A. 2003: Using focus groups to develop culturally relevant instruments. Western Journal of Nursing Research 25, 798-814. 